\title{
A Bilingual Newspaper: An Educational Tool to Empower the Family in the Ethiopian Community as a Basis for its Assimilation in Israeli Society
}

\author{
Lea Baratz \\ Department of Literature, Achva-College of Education, Israel \\ E-mail: lbaratz@netvision.net.il \\ Roni Reingold \\ Department of Education, Achva-College of Education, Israel \\ E-mail: reingold@netvision.net.il \\ Hannah Abuhatzira \\ Achva-College of Education, Israel \\ E-mail: Channahmail3@gmail.com
}

Accepted: November 07, 2012 Published: December 05, 2012

Doi:10.5296/jsr.v3i2.2709ＵRL: http://dx.doi.org/10.5296/jsr.v3i2.2709

\begin{abstract}
The current paper analyzes unique educational texts written of bi-lingual called Nugget News. The analysis of the qualitative interpretive texts has helped to identify power and suppression foci influencing or forming the identity of the members of Ethiopian immigrant community inside the hegemonic environment of the Hebrew-speaking Israeli community. We refer to the concept of multiaccentuality (Wolloshinov, 1973), which defined within social contexts and it symbolizes the system of representations of signs amongst various classes. Within the framework of the social process to which the term is directed the social-cultural group chooses to attribute various accents from its cultural autonomic experience to a given sign. As a result, therefore, a single sign can be interpreted in various ways within the social-cultural classes and multiaccentuality attributed to it by various social groups expresses it as being "a class struggle arena". The newspaper reflects the weakness of visibility while reality emphasizes the visibility.
\end{abstract}

Keywords: Bilingual Newspaper, Ethiopian Family, "Betterness", Success, Education, Multiaccentuality 


\section{Introduction}

"....When we arrived in Israel they sent us to boarding schools so that we would forget our culture of origin. The objective was a "melting pot" - to take people and integrate them into one culture...." (Yediot Negat, September 2008, p. 6). This statement constitutes the background of this paper and seeks to examine by means of the newspaper "Yediot Negat", which is a partisan or a tendentious newspaper, the perception characterizing the absorption processes and the integration of natives of Ethiopia in Israel at present in comparison to the perception that characterized the absorption of immigrants from Ethiopia during the eighties of the twentieth century, when the waves of immigration of this community to Israel began. This paper constitutes a continuation of the paper published in Hed Haulpan Hahadash entitled "Yediot Negat - Multiculturalism as a Pretender! (Baratz, Reingold and Abuatzira, 2010).

"In the eighties the boarding schools were a lifeline"; "The nature of immigration was difficult. They didn't roll out a red carpet for us. We arrived with all our possessions and with harsh experiences of loss in the family from the journey to Sudan" (Maspin, undated). The parents were excluded from the educational process of their children and an example of the pinnacle of this policy is that during the process of placement of the children in special education there was no real inclusion of the parents (Maspin, undated).

A not insignificant part of the children of the Ethiopian community immigrated to Israel without parents, therefore the assumption of the establishment at that time was that the parents should deposit their education in the hands of a governmental body that was to send them to boarding schools of religious character and this was executed almost across the board; this action was one of the most prominent characteristics of absorption in Israel and correlated to the educational policy which supported Jewish religious education.

The division of the Ethiopian family in Israel had fundamental significance as in traditional society the extended family is perceived as the basis of social organization in general. The family, as a legal, political and religious unit, was assigned the task of educating its young. As in the modern environment these roles were given to the State, the relationship was based on definition and achievement of functional objectives only. As a consequence of the distancing of the individual from his natural nuclear society, he received less emotional support. As a result of the division or the collapse of the family the individual pays the price of his life becoming a public asset (Miklace, 2009).

The division of the family unit has led to $22 \%$ of the immigrant children being exposed to neglect; about 15 thousand immigrants, immigrant adolescents and children, have been identified within the framework of the national program for children and adolescents at risk. The parents of $39 \%$ of the immigrant children find it hard to attain the services that they need. There is evidence of large scale exaggerated use of alcohol and drugs (16\%) and abnormal 
behaviour (20\%) amongst immigrants identified aged 12-18 years (as compared to Jewish adults in general identified in the same age groups (10\% and 17\%) accordingly) ("Beta Israel” Publishing House).

The policy of separation of Ethiopian immigrant adolescents from their families began to be examined in depth only during the nineties. "We learnt that the immigration of parents obligates absorption of parents. That is to say: role supported absorption. These are mainly the familial roles....the most important factor in Israeli society, which is a society built on family life (Fogiel-Bijaoui, 2005). That is to say, as the educational system is the central absorbing arena and "it is the meeting place between the individual and the family and between the community and the public" (Fogiel-Bijaoui, 1999), identity preservers and inclusion development processes must be implemented in the immigrant society. In this regard it can be stated that the main task in favourable absorption is the empowerment of abilities and development of feelings of capability and coping (Fogiel-Bijaoui, 2005). That is to say, the assumption was adopted that the "family as an organic unit in all matters relating to its absorption and intervention in methods of its education" should be emphasized (Cohen and Spector, 2003, 11), as well as the assumption that the parents should be defined as "family leaders and absorption guides" (Ibid).

Notwithstanding the exclusion of the parents in the past, at present the parents are enlisted by the Israeli establishment for the purpose of integrating their children into Israeli society. One of the means for this is the publication of a bilingual newspaper called "Yediot Negat", published under the sponsorship of the Ministry of Education and the Steering Centre of Native Ethiopians in the educational system. The publication appears once every two months and is distributed amongst the Ethiopian community in Israel, in high schools and colleges with a distribution of about 22,000 copies. The newspaper started publication on February 1999 and its target population is native Ethiopians and those working with them. The newspaper is written in Hebrew (the language of the majority in Israel) and a third of it is translated into Amharic and Tigrigna (the languages of the Ethiopian immigrants). "Negat" in Amharic means before dawn, meaning hope for the future. The objective of the newspaper is to assist the community in their integration into Israeli society while strengthening the bond with their cultural heritage, their openness to acceptance of life in Israel and intensifying their inclusion in Israeli society. One example of many in regard to the objective served by the newspaper is presented in the following quote from one its readers:

"...The general public is only aware of what they learn from the media as regards wretchedness and non-success. Let's use this day (the Sigd) to convey a message of success...we have still not genuinely been accepted by Israeli society. Only if we succeed in building a stable foundation, based on our heritage, will we succeed in integration and acclimatization in Israeli society...." (Tzega Melco Yediot Negat, Issue 66, 2011).

The current paper, based on research of the 66 editions of the newspaper, seeks to examine whether reading words such as "success" "betterment" "values" in a partisan publication, 
reflects a mechanism through which the State is trying to advance the absorption policy for Ethiopian immigrants, which awards a central role to the family as a broker and promoter of socialization processes. Whilst doing so we seek to try to characterize whether this policy, contrary to the manifested assimilation policy in the past, is multicultural (as can be assumed by use of a bilingual newspaper), or whether there is still an approach of covert assimilation, as such that it can be defined as purported multiculturalism.

Based on the platform of objectives of the newspaper, which appears on the Beta Israel Community internet website, the nature of the newspaper is as an educational tool and the significance of its objectives can be seen to be:

- Empowerment of the community, encouragement to take responsibility for education of its members by means of publication of success stories and contribution of the communities; encouragement of analysis and critical thought processes and development of panoramic observation; publication of narratives and testimonies from the cultural heritage of the community.

Publication of subjects relating to education and society. Discussion and interpretation of social phenomena within the communal and political framework.

- Development of awareness among the community and entities working with them in regard to the various phenomena.

- Hiring reporters from the communities for press reporting with the objective of integrating into the world of media.

Furthermore, the function of the newspaper as an objective-directed tool is demonstrated by one of the editorials, appearing in one of the newspaper editions: "We intend to put the issues relating to the Beta Israel Community on the agenda including those under dispute with the objective of encouraging insightful dialogue within and outside of the community. At the same time we will continue to present success stories and prominent achievements of individuals in order to encourage excellence amongst the youth (Yediot Negat, December 2010).

\subsection{Review of the literature}

According to the school for determining an agenda (Caspi, 1996), the media has a major and essential effect due to their significant power which enables them to raise issues for public dialogue for consideration and action. According to this school the media dictate the public agenda and determine the issues for the general public to consider or discuss. In this matter, one of the fundamental methods of examining the ethical codes of society is to examine the texts assimilated by the community consumers. The press text is a tool used to transfer ethical messages mainly if it is implemented under the sponsorship of the Ministry of Education. The place of the newspaper as a communications tool seeks to examine whether the statements appearing in the media have an objective significance or whether it mediates via selection, framing and interpretation processes which are available to the newspaper as a 
communications media (Galili-Zucker, 2008)? According to her the work process is carried out my means of analyzing Barthes Symbolic Codes which emphasize that "the codes consolidated for the press product in general should interest each of us who unsuccessfully observes the objective reality as compared to the new, which is mediated for us by means of the media" (p. 10). The term framing was first defined by Goffman (1974) as "frameworks which offer perspective and significance". As far as he is concerned the term refers to the method of presentation conveyed during the unconscious selection process, in which the frame of reference of information or an event are presented, which influences the subjective interpretation that an individual provides to certain information or events. The technique of framing is designed by communications methodology using repetition of words, use of expressions, imagery and associations, while converting them to familiar symbols and events. The power of framing in its influence on target populations is expressed by focussing the attention on certain aspects and distancing other aspects.

Schraman and Weimann (Schraman 1964; Weimann 1985; Weimann 1983) refer to the media as a social institution serving the existing social order and in fact preventing other voices from disputing or challenging this order, which creates the illusion of free public space while in practice the media serves the political power thereby creating an infrastructure of dual and even contradictory relationships with the target population and the government. This dual relationship is due to the fact that the government on its part is interested, as far as possible, in creating internalization by the public and prevention of publication of sensitive information which could undermine the dominant ideology. This, while the media on its part acts as an integrated system of interests: the need to maintain economic profitability; the need to compete with rivals; and the need to publish reliable information while at the same time preserving the self image of non-dependence on the government (Reinhart, 2010, p. 39). In order to examine the essence of the media Reinhart refers to three criteria: the type of information provided, analysis of the content of the information including the basic claims and central themes as well as linguistic analysis - which relates to the method of presenting language and the ethical baggage derived from it.

To examine the linguistic aspect and the ethical significance derived from it, we are required to refer to the concept of multiaccentuality (Volloshinov, 1973), which represents a component of the natural social process. As far as Volloshinov is concerned "multiaccentuality" is defined within social contexts and it symbolizes the system of representations of signs amongst various classes. Within the framework of the social process to which the term is directed the social-cultural group chooses to attribute various accents from its cultural autonomic experience to a given sign. As a result, therefore, a single sign can be interpreted in various ways within the social-cultural classes and multiaccentuality attributed to it by various social groups expresses it as being "a class struggle arena". Within the framework of this "struggle" the social-cultural group chooses to impose various accents on the sign in order to customize it according to its social ideology and thereby to attribute it exclusively to themselves. Therefore, examination of the use of the term success asks to expand that which is incorporated in the denotative essence of the term whereby the basic 
definition is derived from the dictionary. Social meanings are added to the dictionary definition and they specifically clarify the educational meaning which the current paper is attempting to examine.

\subsection{Success, identity and visibility}

When we are dealing with an issue related to absorption processes of immigrants, we must examine the relationship between the success of the immigrant, as interpreted by one and the absorbing society, and the nature of the identity that develops within the framework of the dynamic social process that the individual being absorbed and the absorbing entity operate in.

Social identity exists within the framework of social, cultural and ideological relationships and language is used within the framework of these relationships as social practice. Lumpsky Feder, Rappaport and Ginsberg (2010) use the term "visibility" as part of the identity building process in order to understand the phenomenon of immigration. As far as they are concerned they seek to see the phenomenon of immigration as a multidimensional issue replete with internal contradictions. The analytical power of the term visibility is by its placement in the centre of the dichotomous perception of "to see and be seen" of the local population and the immigrant. This perception points to the various ways which the "to see and be seen" are interwoven and together play the social game of social inclusion and exclusion, of inclusion and rejection, of demarking and hiding. Disassembly of these dichotomies, submerged in the very visibility, enables a connection between the phenomenological aspects of immigration and the social structuring of the immigrants. In this way visibility connects between the demands raised by the absorbing society before the various groups of immigrants and the various and diverse strategies which the immigrants use within the framework of finding a place for them. This while accentuating aspects of identity of both the individual and the group. The accent on the element teaches about the placement processes of the immigrants with the body from a new and fascinating aspect. Moreover, the term visibility enables a connection between physical visibility in spaces of everyday life and the symbolic visibility found in the field of discourse. In the initial decades following the establishment of the State of Israel the social and educational policy known as "the ingathering of exiles" or "melting pot" dominated (following the name given to a similar policy in the United States). At the basis of this viewpoint of open assimilation was the desire to distance the Jewish immigrants from the Islamic countries and their community cultures and to integrate them into the framework of what has been defined as the Israeli culture, that is to say the hegemonic and dominant culture, which was a variation on the culture of the absorbing Ashkenazi elite (Sever, 2001). The objective of the melting pot policy was to conceal the visibility of the immigrants and thereby cause the creation of a negative visibility, which was derived from contempt for their culture and continual discrimination (Resnick, 2010). This perception brought about a struggle against the melting pot and the national collective identity perception and the promotion of the multicultural concept, which gave birth to the need for newspaper reporting which reflects the face of the Ethiopian society. 


\section{Mll Macrothink}

Journal of Sociological Research

ISSN 1948-5468

2012, Vol. 3, No. 2

The open assimilation approach is based on the view that the particular and inferior cultures of minority groups must disappear. In comparison to this monistic approach, the pluralist approach consciously espouses the existence of various cultures in one political/social entity and even considers this to be normal (Lam, 5756). However "the pluralistic separation of societies points to the vision of a repaired world in the ideology of pluralism....rather it is possible that in its field there is a place for aspiration....to meld the cultures of the various groups, which could be realized specifically as a result of the recognition of their right to exist" (Ibid, p. 212). That is to say, the pluralistic mono-cultural version is in fact a perception that espouses covert assimilation. Its target is identical to the open assimilation target. The recognition of the right of the ethnic groups and communities to preserve their separate cultures is a necessity and even more so a pretence or even a false recognition.

However, pluralism can also serve as a basis for multicultural perceptions. The multicultural pluralism ideology does not ask the communities to revoke their unique cultures but rather asks them to establish a dialogue, in the cultural boundary areas, between the various cultural groups, who preserve their particular cultures (while recognizing these cultures and from a position of pride), this without the perception of cultural hierarchy or an attempt for cultural colonialism (Reingold, 2005; Reingold, 2009). Educational expressions of this ideology are expressed by constructing shared educational public spaces for community members of various cultures, or by a preliminary stage of dedication of separate educational public spaces for minority group cultures in order to empower the members of the community and introduce them to intercultural dialogue from a position of strength, that is to say to incorporate the preliminary stage of particular multiculturalism (Reingold, 2007).

The canonical dialogue tends to reinforce social categories as part of the social fabric. "Multiaccentuality" refers to the capability of a sign to receive various significances amongst the various classes. The significance changes/fills with content according to economic and social interests (Voloshinov, 1973), therefore in regard to this theory it is appropriate to examine how the Beta Israel community adopts the meaning of success and which accents it chooses, as a society that is being absorbed, to attribute to this term in order to customize it according to its exclusive orientation.

\subsection{The Ethiopian Community in Israel}

The community of Jews of Ethiopia is searching for the "right" place for it in the Israeli social fabric as regards its dimension of visibility or invisibility (Ben Ezer, 2010). On the one hand the group aspires to be visible and at the same time to be invisible. On the one hand it seeks to become an integral undifferentiated part of the society it has come into, and therefore also a process of an attempt to integrate into the society has been started by the immigrants, however on the other side it seeks to preserve its uniqueness. That is to say the group seeks to continue to maintain important aspects of its previous existence, from its social cultural past (Ben Ezer, 2010 Paz and Almog, no year) 


\section{Methodology}

\subsection{The aim of the Research}

This paper seeks to describe the discourse raised in articles appearing in the "Yediot Negat" newspaper with the objective of identifying and analyzing the centres of power empowering the concept of the Beta Israel family in Israel.

We wish to examine within the framework of the canonical discourse as to how the Beta Israel community brands its identity by means of a linguistic sign which strives under normative signs of the signifiers, this while examining the recognition of the words "success" and "excellence" in the "Yediot Negat" publication, as testifying to an attempt to delete the visibility of the traditional family model while simultaneously becoming a key motif in building the success model, which creates visibility with a new identity amongst the Ethiopian family in Israeli society.

The research method is qualitative-interpretive and deductive, based on analysis of the multi-aspect critical discourse (Klein, 2010) and investigates social-cultural relationships and the covert significances derived from them, this according to Van Dijk (Van Dijk 1991, 2001).

\subsection{The Research Process}

The start of the research process included reading all the newspapers and preparation of a list of issues presented therein, according to the principle of the essence of the central concept of the article. Determination of the issues led to definition of categories which represent the connection between the articles (Baratz, Reingold and Abu Hazerira, 2010). Further we focussed on the categories selected as establishing the research assumption, this according to Shakedi's view (2010) whereby the categories take into account the cultural context and the relationships of place and time of the researched phenomena.

Within the framework of the analysis mapped content design was performed, that is the finding of a shared conceptual perspective which arranges the first categories on 2 axes: a horizontal axis which identifies the super-categories and the vertical axis which describes the sub-categories. The two axes enable identification of the full potential of the data collected.

The sampling method: Tracking the appearance of words was performed systematically from within all the newspapers. On presenting the findings samples were presented that clearly indicated the phenomenon that we were searching for.

\subsection{Findings}

Hereinafter we shall present the findings which were identified in the content analysis; the 


\section{Macrothink}

findings refer to the words which established the success or betterment motif, which constitute means of betterment in the family tapestry. The findings are arranged in structural sequence which exhibits the development of the place of the parents in the education system, as demonstrated in the newspaper:

The place of the parents/family within the framework of the educational process in traditional culture:

"...When a teacher in Ethiopia, whose authority is considerable, would call the parents they would come immediately...the educational system removed responsibility from the parents...the parents felt that here in Israel nothing was expected of them....(Negat, September 2008, p. 8).

"In Ethiopia parents would buy all the equipment for school once. Here I keep on explaining to them that if they want a good home they have to study..... (Negat, April 2010, p. 8).

“...My eldest daughter studied in Ethiopia up to $6^{\text {th }}$ grade and knew how to respect the teacher, how to study and how important studies are. In Israel children do not understand that it is their duty to study, and the teachers do not hold them short....the children have no respect for teachers...." (Negat, April, 2010, p. 8).

"...We put back into the home what we had in Ethiopia...the children learnt from the parents how to work and how to behave...." (Negat, March, 2009, p. 6).

The indications of change of policy from exclusion of parents to parental dominance in structuring the model of excellence:

"...When the parents are involved - it is possible to succeed....the school proves that investment in education and partnership with the parents leads to high achievements...." (March, 2011, p. 3).

"....A lot is dependent on the parents...." (Negat, July, 2007, p. 4).

"...and the importance of the parental workshops....strengthens the parents' authority...." (Negat, July 2007, p. 3)

"....When there is a strong and supportive family...the situation is different....it requires an effort by the parents....parental workshops should be held.... authority should be returned to the father....." (Negat, July 2007, p. 4)

“...The parents are responsible for their children....." (Negat, January, 2008 p. 8).

"....The parents need to take care of their children, the older brothers take care of the younger brothers....." (Negat, September, 2009, p. 2). 
"...It is very hard to succeed without the support of the family...." (Negat, September, 2008, last page).

“...My family also has a part in my strengths....” (Negat, September, 2009, p. 6).

“...The parents lead change....” (March 2011, p. 15)

“....The parents' patrol in Ramat Eliyahu in Rishon Lezion patrols the area at night so that the adolescents know that they have someone to talk to...." (Negat,March, 2011, p. 7)

\section{Discussion}

The focus of the current discussion is one of the main reasons that the absorption of the Ethiopian Jews in Israel is not a success story, to say the least: the absorption policy (in general and those relating to education in particular) was based, at its outset, on the principle of open assimilation and absorption processes of the adolescents in the educational systems, in particular boarding schools, while excluding the parents almost totally and the dismantling of the nuclear family.

This exclusion policy began to cease in the nineties, when it was understood that the nuclear family should have a central position in the absorption processes as a mediator and promoter of socialization processes, this by means of empowering the parents. However, as our research teaches, the melting pot policy has not ceased and open assimilation has been replaced with covert assimilation and not with a multicultural policy.

An analysis of the qualitative interpretive texts which we performed on articles from the "Yediot Negat" newspaper, which is a partisan newspaper, discovered repetitive use of two words "betterment" and "success". Examination of the occurrence of these words testifies that they have become a key motif in building the success model which deletes the visibility of the Ethiopian community within Israeli society as they then become equals in their own eyes and equal in the eyes of the absorbing society. Through writing about these issues, an ideology has been formed which seeks to encourage aspiration to excellence amongst adolescents. This trend of betterment serves a trend which is designed to empower the community in its own eyes, however simultaneously it also becomes an obstacle for the community, this as the veteran Israeli society does not see the successes of the community as a cancellation of visibility, but rather as an element that emphasizes the visibility of the community. If the newspaper's objective is to strengthen the invisibility of the community then the disclosed content testifies specifically to visibility. It presents a weak group as the contents, which appear to be empowering, expose the face of the community. Specifically the need to highlight visibility testifies to the weakness of the community in the eyes of the Israeli absorbing society. The very writing about the issue and the way in which the issues are presented illustrates a strong desire to present the community as a community which has succeeded in integrating into Israeli society and not having withdrawn from them, however in 
practice the use of the newspaper, which dedicates a broad verbal volume to the question of integration and success, indicates that these issues are executed artificially and by means of the mediation of those requesting it. That is to say, when the way in which the Beta Israel community perceive themselves is examined, the newspaper constitutes a tool emphasizing the visibility and also the reality perceived in the place in which the emphasis of visibility processes exists. However, when we examine the way in which the Beta Israel community seeks to be visible in the eyes of the absorbing society, there is a contradiction between the newspaper and reality. The newspaper reflects the weakness of visibility while reality emphasizes the visibility. In this regard, our findings show that within the multaccentuated framework which attributes various signs to social groups, the community is trying to attribute these accents to the term "success" in order to lead to the deletion of visibility, however simultaneously the process leads specifically to the emphasis on visibility and therefore as a result the community does not succeed in "the class struggle arena" that the sign is related to, as it leads to the opposite result from that which it aspired to from the outset - emphasis of visibility instead of deletion.

Unfortunately when we examine the perception by the absorbing society of the community in practice, it becomes clear that both in the newspaper and in reality weakening processes of visibility become apparent. Therefore the newspaper serves the trend of the community in its own eyes and not as it wishes to be perceived in the eyes of the absorbing society. This is presented in brief in the following flowchart:

It would seem that the social objective that the State is offering within the framework of the absorption process of the community, specifically loses the authentic direction for which it was designed, due to the multiaccentuations that the community as a social cultural group chooses to award to terms such as success. The flowchart indicates how the direction of the multicultural policy, specifically in regard to the Ethiopian community, blurs and even changes direction when it uses the parents as promoters of absorption and integration; it is possible that this is due to the different viewpoint which the immigrants take and their different perception of the terms such as "success", than that intended by the absorbing State.

Notwithstanding the integration of the parents in the absorption processes (and this although the widespread boarding school system has not been cancelled) and the emphasis on the "success stories" among the community members (officers in the IDF, holders of academic degrees etc) reduced the feelings of alienation and frustration amongst some of the community, it is appropriate in our opinion that the covert assimilation absorption policy shall be replaced by a multicultural policy. Integration of multicultural education in separate and shared public spaces (in other words, of particular multicultural education and pluralistic multicultural education) can assist in genuine integration of the Ethiopian community in Israel. Only thus can they become genuine family members of Israeli society and feel that here they are at home. The Yediot Negat newspaper, similar to other educational tools such as children's literature and bilingual essays, can only have a significant contribution to this process. 


\section{Bibliography}

Ben Ezer, G (2007). The Journey - Stories of the Journey of the Ethiopian Jews 1977-1985. Beit Shemesh: Modan Publishing House. (in Hebrew)

Ben Ezer, G (2010). "As a drop returning to the sea?" Visibility and invisibility in the absorption process of the Ethiopian Jews, from A. Lumski Feder and T. Rapaport Editors. Visibility in immigration - body, a representative view (pp. 305-328). Jerusalem, Van Leer Institute and Hakibbutz Hameuhad. (in Hebrew)

Baratz, L, Reingold R and Hannah Abuhazeira, (2010) Yediot Negat - Pretend multiculturism, Hed Ha'ulpan 97, pp. 71-80. (in Hebrew)

Baratz, L. Reingold. R. \& Abuatzira, H. (2011). Bi - lingual newspaper as an expression of a Fake multicultural educational policy in Israel. International Education Studies 4 (4), 160-167. Barthes, R. (1974). S/Z An Essay (R. Miller, Trans) New York: Hill and Wang.

Caspi, D., \& Elias, N. (2008). Two media systems: media of and for the benefit of minorities in Israel. Kesher, 37, 99-109. (in Hebrew)

Cohen R. \& Spector G. (2003). Cultural-empowerment mediation - immigrant parents from Ethiopia in a cultural meeting place. Published by the Ministry of Education, Culture and Sport - Adult Education Division. (in Hebrew)

Fogiel-Bijaoui, S. (2005). Families in Israel: Post Modernity, Feminism and the State, in J. L. Roopnarine \& U.P. Gielen (Eds), Families in Global Perspective (pp. 184-204). Boston: Allyn \& Bacon.

Goffman, E. (1974). Frame Analysis: An Essay on the Organization of Experience. New York, NY

et al: Harper \& Row.

Galilee-Tzuker, A. (2008). Orit Galili, Contemporary communication politics: Online civics in an online era, Ramot Online Publishing House, Ramat Aviv: Tel Aviv University.

Lumpaski Feder, Rapaport and Gindsburg 2010: Introduction: Visibility in Immigration body, view, representation, from: A. Lumpsky Feder and T. Rapaport (Editors). Visibility in immigration - body, view, representation (pp. 11-42). Jerusalem: Van Leer Institute and the Kibbutz Meuhad. (in Hebrew)

Lam, Z (5756). The pluralism concept and its implementation in Israeli education. From A. Gur-Zeev (Editor) Education in the Era of Post-Modern Discourse (207-220). Jerusalem: Magnus Publishing House. (in Hebrew)

Maharta, D (2008). How to correctly absorb immigrants in the educational system, Position Paper: Emergency situation and Ethiopian emigrants. Retrieved on July $16^{\text {th }} 2011$ from:

http://mercas-higui.org.il/pagesposition.aspx?id=3

Maspin, A. (undated), Boarding school students, parents and in between them. Kav Haofek Magazine, retrieved on July $18^{\text {th }} 2011$ from:

http://www.iaej.co.il/newsite/content.asp?pageid=145

Mana, A, Or A. and Mana Y (2004). The identity of adolescents from Ethiopia and the Commonwealth of Independent States: Organizational principles of unique cultural representation of immigrant absorption. Magamot, 43, 491-519. (in Hebrew)

Mana, A, Or A. and Mana Y. (2007). Theoretical, social representations of social identity and 
the meeting between cultures: an integrative model of social formation of adolescent identities, Magamot, 45, 24-52. (in Hebrew)

Sever, R (2001). Mingling or integration? A conceptual framework for examination of the issues of multiculturalism. Gadish, 7, pp. 45-54. (in Hebrew)

Sever, R (2007), The Language of Absorption: Absorption of immigrants with the aid of active encouragement to preserve the mother tongue and intercultural mediation in education, from: O. Perry (Editor), Education in a multicultural society (pp. 64-104), Tel Aviv: Carmel Publishing House, 67-104. (in Hebrew)

Miklace, S.1, Y (2009), Severance of Ethiopian children from their families by the Welfare Services with intolerable ease - ways of coping. Retrieved on July $15^{\text {th }} 2011$ from:

http://pkidat-saad.blogspot.com/2009/04/blog-post.html

Paz, D and Almog, A (no year). The immigration crises from the People of Israel website, retrived on July $20^{\text {th }}$ 2011, from: http://www.peopleil.org/details.aspex?itemID=7681

Klein, A (2010). Analysis of the critical discourse of newspapers, from L. Kassan and M. Kromer - Nevo (Editors). Analysis of the quantitative research data (pp. 230-254), Ben Gurion University Publishing House. (in Hebrew)

Reingold, R (2009). Multicultural ideology: Educational terms, polemics and implications, Massad 7, 6-13. (in Hebrew)

Reingold, R (2005). Curricula models of multicultural and pluralistic education - four case studies from academia in the United States, Dapim 40,108-131. (in Hebrew)

Reinhart T. (2010). It is written in the newspaper - language, communication and ideology, Editor: Ran Hacohen, Tel Aviv, Resling.

Resnick, G. (2010). Visibility and identity in multicultural schools in Israel, in: A. Lomsky-Feder and T. Rapoport (editors), Visibility at immigration - body, view, representation (pp. 274-302). Jerusalem: Van Lir Institute and Ha-Kibbutz ha-Meuhad (in Hebrew).

Shakedi, A (2010). Theory based in narrative: Structuring of theory in qualitative research. From: Analysis of qualitative research data, Editors: L. Kasso and M Cromer Nevo (pp. 436-461). Ben Gurion University Publishing House.

Schraman, L. w. (1964). Mass media and National Development. Stanford: Stanford University Press.

Van Dijk,T.A. (1991). Racism and the Press. London: Rutledge.

Van Dijk,T.A.(1988). News Analysis. Case studies of international and national news in the press. Hillsdale, NJ: Erlbaum.

Voloshinov, V.N (1973). Marxism and the Philosophy of language. New York \& London: Seminar Press.

Weimann, G. (1985). "Terrorist or Freedom Fighters? Labeling Terrorism in the Israeli Press", Political Communication and Persuasion, 2(4): 433-445.

Weimann, G. (1983). "The Theater of Terror: The Effects of Press Coverage", Journal of Communication, 33: 38-45. 